\title{
SÍNTESE DE REGIOISÔMEROS QUIRAIS A PARTIR DE D-MANITOL: OBTENÇÃO DE UMA MISTURA DE ÁLCOOIS ACETILÊNICOS
}

\author{
Antônia Maria das Graças Lopes Citó*, Bruno Quirino Araújo e José Arimatéia Dantas Lopes \\ Departamento de Química, Centro de Ciências da Natureza, Universidade Federal do Piauí, Campus Ministro Petrônio Portela, \\ 64049-550 Teresina - PI, Brasil
}

Aderbal Farias Magalhães e Eva Gonçalves Magalhães

Instituto de Química, Universidade Estadual de Campinas, CP 6154, 13083-970 Campinas - SP, Brasil

Recebido em 5/12/08; aceito em 26/5/09; publicado na web em 28/10/09

\begin{abstract}
SYNTHESIS OF CHIRALS REGIOISOMERS FROM D-MANNITOL: OBTAINMENT OF A ACETYLENIC ALCOHOLS MIXTURE. The synthesis of chiral acetylenic regioisomers was described by using an appropriate intermediate such as isopropylidene glycerol, a synthon widely used in the enantioselective syntheses. This intermediate was prepared from D-mannitol. The nine obtained compounds have been characterized by their respective spectral data. The mixture of chiral acetylenic alcohols showed activity against Escherichia coli when tested through the monitoring of $\mathrm{CO}_{2}$ released during microbial respiration by using a conductimetric system.
\end{abstract}

Keywords: D-mannitol; acetylenic alcohols; E. coli.

\section{INTRODUÇÃO}

D-manitol (1), um composto poli-hidroxilado, opticamente ativo, e obtido da redução de carboidratos, é um importante substrato de partida em síntese, por formar pequenos blocos de construção quirais (small chiral building blocks). ${ }^{1}$ Os derivados acetonídeos de D-manitol são intermediários de diversos compostos enantiomericamente puros e biologicamente ativos, destacando-se o seu derivado cetal cíclico de cinco membros, hidroxilado, o isopropilideno glicerol (4), um precursor quiral, usado como agente hidrófilo em penetração transcutânea de agentes ativos, ${ }^{2}$ e como synthon quiral, na síntese enantiosseletiva de uma grande variedade de produtos naturais, tais como AZT e outros inibidores de $\mathrm{HIV},{ }^{3,4}$ leucotrienos, ${ }^{5,6}$ prostaglandinas, ${ }^{7}$ PAF (Platelet activating factor), glicerofosfolipídeos, $\beta$-bloqueadores, ariloxipropanolaminas, ${ }^{8}$ dentre outros.

A multirresistência de cepas de Escherichia coli (E. coli) a antibióticos tem provocado a morte de pessoas por toxinfecção, através da infecção bacteriana, contraída da ingestão de água e alimentos contaminados. A E. coli é uma bactéria bacilar natural da flora microbiana do trato intestinal do homem; no entanto, a ação das toxinas de cepas de $E$. coli nas células de mamíferos inibe a síntese proteica levando à morte celular..$^{9,10} \mathrm{De}$ acordo com o CDC (Centers for Disease Control and Prevention), ${ }^{11} 18 \%$ de todos os casos de infecção por $E$. coli são hospitalizados, 3,6\% desenvolvem insuficiência renal aguda (IRA), 1,9\% morrem e alguns desenvolvem insuficiência renal crônica (IRC).

Os álcoois acetilênicos, substâncias isoladas de vegetais superiores como Panax Ginseng, ${ }^{12}$ fungos e organismos marinhos como algas e esponjas, ${ }^{13}$ têm mostrado relevância quanto ao aspecto sintético-configuracional ${ }^{14}$ e farmacológico, por apresentarem um amplo espectro de atividades biológicas: antitumoral,,$^{15}$ anticâncer, citotóxica, ${ }^{13,15}$ antineurogênica, ${ }^{16}$ antifúngica, antivirótica e antimicrobiana. ${ }^{17}$

Nesse sentido, o objetivo deste trabalho foi sintetizar álcoois acetilênicos a partir de D-manitol e verificar sua atividade antibacteriana contra E. coli.

\footnotetext{
*e-mail: gracacito@gmail.com
}

\section{RESULTADOS E DISCUSSÃO}

A mistura de álcoois acetilênicos foi sintetizada via synthon quiral 4 de acordo com o Esquema 1. A síntese estereosseletiva do isopropilideno glicerol foi realizada a partir do diacetonídeo 2 conforme procedimento descrito na literatura. ${ }^{18-20}$ As etapas realizadas até a obtenção da mistura quiral foram bem sucedidas com rendimento global de $28 \%$.

Inicialmente, realizou-se a proteção ${ }^{18}$ do D-manitol (1) e o produto protegido 2 sofreu clivagem oxidativa com periodato de sódio, fornecendo o derivado aldeído isopropilidênico $3 .{ }^{19} \mathrm{O}$ aldeído obtido, por se tratar de um composto bastante instável, foi utilizado sem purificação prévia. Na etapa seguinte, o composto 3 foi reduzido com boroidreto de sódio conduzindo ao derivado acetonídeo hidroxilado $4 .^{20}$

O cetal cíclico $\mathbf{4}$ foi alquilado via derivado tosilato $\mathbf{5}$ através da reação com organocuprato e n-butil lítio, ${ }^{20,21}$ obtendo-se o composto 6. Posteriormente, realizou-se a desproteção do cetal alquilado $\mathbf{6}$, com ácido clorídrico diluído. Nesta etapa, evitou-se a exposição ácida prolongada devido à facilidade do grupo isopropilidênico sofrer hidrólise, e obteve-se o heptanodiol quiral 7 com $95 \%$ de rendimento. Seguindo a sequência de síntese do Esquema 1, preparou-se o derivado epóxido 10 via os acetoxibrometos 8 e $9,{ }^{22,23}$ isto é, (S)-2-acetoxi-1-bromo-heptano e (R)-1-acetoxi-2-bromo-heptano, obtidos na reação do diol 7 com solução saturada de ácido bromídrico em ácido acético. O produto bruto foi purificado em coluna cromatográfica de gel de sílica eluída com diclorometano, rendendo uma mistura dos compostos 8 e $\mathbf{9}$, sendo o composto 8 majoritário (94\%), o que foi confirmado através da análise do espectro de $\mathrm{RMN}$ de ${ }^{1} \mathrm{H}$ da mistura; este resultado evidenciou uma alta regiosseletividade nesta reação.

A mistura de regioisômeros de acetoxibrometos não foi separada, uma vez que ambos produzem o mesmo epóxido. O (S)-1,2-epoxiheptano (10) foi preparado tratando-se a mistura dos regioisômeros $\mathbf{8}$ e 9, com hidróxido de potássio em metanol. ${ }^{24}$ Após tratamento usual, o solvente foi eliminado por destilação fracionada, utilizando-se uma coluna de Vigreux. O óleo incolor 10 foi obtido com rendimento quantitativo.

Com a obtenção do (S)-1,2-epoxi-heptano (10), realizou-se a reação de alquinilação, através da abertura do epóxido com fenilacetileto de lítio $^{25}$ e trifluoreto de boro eterato. $\mathrm{O}$ fenilacetileto de lítio foi preparado utilizando-se fenilacetileno recém-destilado. A reação de alquinilação forneceu $70 \%$ de rendimento da mistura de 
<smiles>C[C@H](O)[C@@H](O)[C@@H](O)CO</smiles><smiles>CC1(C)OC[C@H]([C@@H](O)[C@H](O)[C@H]2COC(C)(C)O2)O1</smiles><smiles>CCCC1(C)OC[C@@H](C=O)O1</smiles><smiles>CCCCC[C@H]1COC(C)(C)O1</smiles><smiles>CC1(C)OC[C@@H](CO)O1</smiles><smiles>CC1(C)OC[C@@H](CO)O1</smiles>

4<smiles>CCCCC[C@H](C)COC(=O)OC[C@@H](Br)CCCCC</smiles>

8

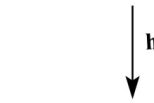<smiles>CCCCCC1CO1</smiles>

10 i<smiles>CCCCCC[C@H](O)CC#Cc1ccccc1</smiles>

Esquema 1. Rota sintética para obtenção da mistura de álcoois acetilênicos quirais a partir de D-manitol. (a) $\mathrm{ZnCl}_{2}$, Acetona, $0^{\circ} \mathrm{C} 30 \mathrm{~min}$, t.a. $2 \mathrm{~h}$; (b) $\mathrm{NaIO}_{4}, \mathrm{H}_{2} \mathrm{O}, \mathrm{O}^{\circ} \mathrm{C} 30 \mathrm{~min}$, t.a. $1 \mathrm{~h}$; (c) $\mathrm{NaBH}_{4} ; \mathrm{EtOH}, \mathrm{O}^{\circ} \mathrm{C}, 2 \mathrm{~h}$; (d) $\mathrm{TsCl}$, Piridina, $\mathrm{O}^{\circ} \mathrm{C}$, t.a. $12 \mathrm{~h}$; (e) BuLi, $\mathrm{CuI}, \mathrm{Et}_{2} \mathrm{O},-78^{\circ} \mathrm{C}$; (f) $\mathrm{HCl}, \mathrm{MeOH}$, refluxo $4 \mathrm{~h}$; (g) $\mathrm{HBr} / \mathrm{HOAc}, \mathrm{O}^{\circ} \mathrm{C}$, t.a. $30 \mathrm{~min}$; (h) $\mathrm{KOH}, \mathrm{MeOH}$, t.a. $20 \mathrm{~min}$; (i) I. $\mathrm{C}_{6} \mathrm{H}_{5} \mathrm{CCH} / \mathrm{BuLi}, \mathrm{THF},-78^{\circ} \mathrm{C}, 10 \mathrm{~min}$; II. $\mathrm{BF}_{3} \mathrm{Et}_{2} \mathrm{O},-78^{\circ} \mathrm{C}, 30 \mathrm{~min}$

regioisômeros 11 e 12 na proporção 91:9, conforme a integração dos sinais de RMN de ${ }^{1} \mathrm{H}$ carbinólicos em $\delta 3,82$ e 3,50, respectivamente.

No sentido de justificar a alta regiosseletividade da alquinilação na formação do isômero $\mathbf{1 1}$ propomos o mecanismo ${ }^{26}$ mostrado no Esquema 2. O maior impedimento estereoquímico no carbono C-2 de $\mathbf{1 0}$ favorece a formação do regioisômero $\mathbf{1 1}$.

A mistura dos novos regioisômeros quirais $\mathbf{1 1}$ e 12, com alta porcentagem do regioisômero $\mathbf{1 1}$ foi submetida a teste de atividade frente à cepa de $E$. coli (ATCC 25922), através do monitoramento de $\mathrm{CO}_{2}$ liberado na respiração microbiana, utilizando-se o sistema de análise por injeção em fluxo (FIA)-Condutométrico. Na concentração de $20 \mathrm{mg} \mathrm{L}^{-1}$, a mistura de álcoois acetilênicos apresentou atividade inibitória maior que $70 \%$ sobre o crescimento de $E$. coli, possivelmente devido à presença do grupo fenila ligado ao carbono acetilênico e da cadeia hidrofóbica. Estes fatores estruturais são importantes para a atividade antibacteriana desta classe de compostos. Considerando o efeito antibacteriano de imidas cíclicas, e sabendo que a ligação dupla no anel imídico é o principal fator da estrutura-atividade, Andricopulo et al. ${ }^{27}$ avaliaram a atividade de imidas cíclicas frente a cepas de $E$. coli e concluíram que grupos polares conjugados ao anel imídico e efeitos estéricos presentes nas moléculas também influenciam na interação com o receptor biológico. Não foi avaliada a contribuição de cada álcool acetilênico separadamente.
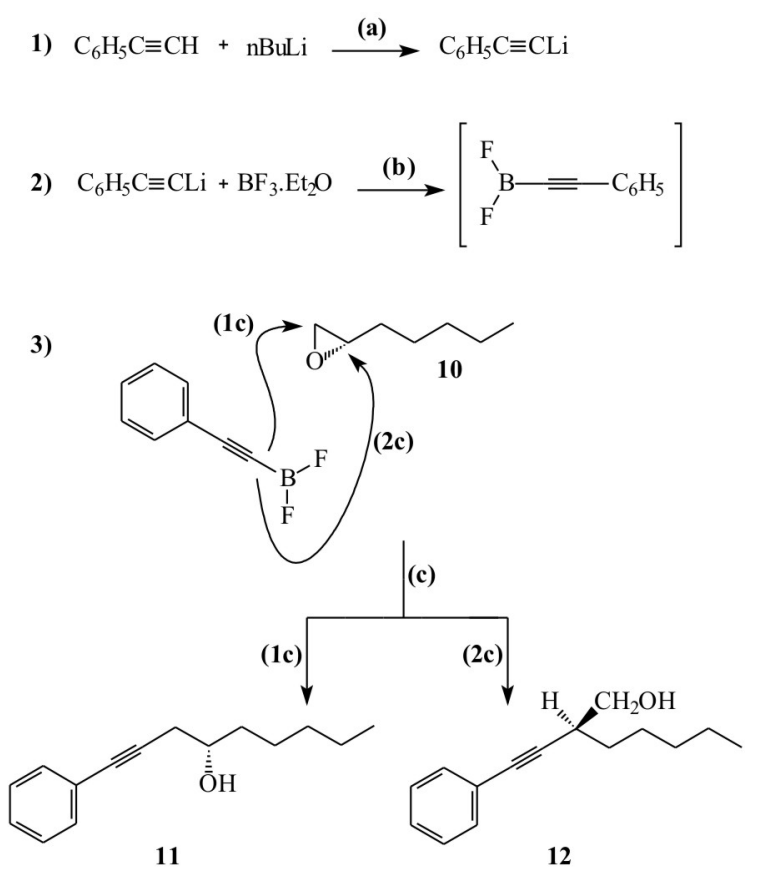

Esquema 2. Mecanismo proposto para a regiosseletividade da reação de alquinilação na formação do regioisômero 11

A correlação dos álcoois acetilênicos da mistura de regioisômeros (Figura 1) com a atividade antibacteriana está evidenciada na planaridade das moléculas, que possibilitam uma melhor interação do aceptor estrutural com o receptor biológico, favorecendo a adição de grupos sulfidrilas da enzima do sistema vital da bactéria patogênica à tripla ligação dos álcoois quirais. ${ }^{27}$ Quanto à quiralidade dos compostos, é possível que as diferentes propriedades farmacodinâmicas e farmacocinéticas determinem seletivamente a interação entre os centros quirais destas moléculas e os sistemas de reconhecimento quiral, em processos biológicos. ${ }^{28}$

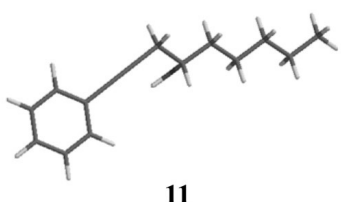

11

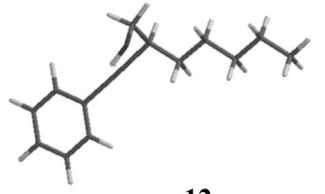

12
Figura 1. Estruturas de menor energia dos álcoois acetilênicos quirais 11 e 12. As buscas conformacionais foram realizadas com o programa Spartan Pro (campo de forças MMFF94). Os confôrmeros de menor energia foram otimizados com método semi-empírico AM1

\section{PARTE EXPERIMENTAL}

\section{Procedimentos gerais}

As cromatografias em camada delgada (CCD) foram efetuadas

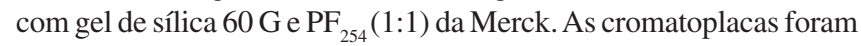
reveladas por nebulização com solução de ácido sulfúrico:metanol (1:1) ou solução ácido acético:ácido sulfúrico:anisaldeído (50:1:0,5) e posterior carbonização em placa de aquecimento. A cromatografia em coluna (CC) foi feita com gel de sílica 60 G (0,02-0,20 mm) da Merck. A cromatografia em camada espessa circular (CCEC), acelerada radialmente, foi realizada em Chromatotron, utilizando 
como fase estacionária gel de sílica $\mathrm{PF}_{254}$ da Merck e sulfato de cálcio $10 \%$. Os valores de $[\alpha]_{D}$ foram medidos em polarimetro Carl Zeiss Jena Polamat A. Os espectros de RMN de ${ }^{1} \mathrm{He} \mathrm{e}^{13} \mathrm{C}$ foram obtidos em espectrômetro Bruker Avance 300 nas frequências de $300 \mathrm{MHz}\left({ }^{1} \mathrm{H}\right)$ e $75,5 \mathrm{MHz}\left({ }^{13} \mathrm{C}\right)$, em $\mathrm{CDCl}_{3}$ ou $\mathrm{CCl}_{4}+\mathrm{CDCl}_{3}$ utilizando como padrão de referência interna o tetrametilsilano (TMS). Os deslocamentos químicos $(\delta)$ foram expressos em ppm e as constantes de acoplamento (J) em Hertz (Hz). Os espectros de infravermelho (IV) foram obtidos em espectrofotômetro Perkin-Elmer FT-IR, em filmes sobre cela de $\mathrm{NaCl}$. Os valores das absorções estão expressos em número de onda $\left(\mathrm{cm}^{-1}\right)$. Os espectros de massas (EM) foram obtidos em um espectrômetro Varian Mat 311 por impacto eletrônico de 70 eV e em um espectrômetro de massas HP 5970 acoplado a um cromatógrafo a gás HP 5890-II.

\section{Atividade antibacteriana}

A cepa padrão de E. coli (ATCC 25922) foi cedida pelo Laboratório de Análises Microbiológicas do Hospital das Clínicas (HC) da UNICAMP. A atividade antibacteriana foi avaliada pelo sistema FIA-Condutométrico por monitoramento do $\mathrm{CO}_{2}$ produzido na respiração bacteriana de $E$. coli em meio de cultura, de acordo com o procedimento descrito por Gimenez ${ }^{29}$ utilizando uma concentração de $20 \mathrm{mg} \mathrm{L}^{-1}$ de amostra. Nos ensaios, a amostra foi considerada ativa, quando proporcionou cerca de $70 \%$ de inibição da respiração microbiana, após 120 min em relação ao controle.

\section{(S)-(+)-1,2-O-isopropilideno glicerol (4) $)^{19,20}$}

A uma solução de cloreto de zinco $(63,39 \mathrm{~g}, 0,495 \mathrm{~mol})$ em 500 $\mathrm{mL}$ de acetona, adicionou-se D-manitol (1) (50 g, 0,275 mol), sob agitação a $0{ }^{\circ} \mathrm{C}$ por 30 min e à temperatura ambiente durante $2 \mathrm{~h}$. Para tratamento usual, adicionaram-se $250 \mathrm{~mL}$ de clorofórmio e $250 \mathrm{~mL}$ de solução saturada de cloreto de sódio. A fase aquosa foi extraída com 3 x $150 \mathrm{~mL}$ de clorofórmio, a fase orgânica foi lavada com 2 x $300 \mathrm{~mL}$ de solução de hidróxido de amônio 5\% (v/v) e tratada com sulfato de sódio. O solvente foi eliminado a vácuo em evaporador rotativo. Em seguida, ao resíduo foi adicionado éter de petróleo e aquecido até ebulição por $30 \mathrm{~min}$. O manitol não reagido foi removido por filtração a quente e o produto cristalino 2 foi recristalizado, com $65 \%$ de rendimento.

A uma suspensão de (2) (+)-1,2:5,6-di- $O$-isopropilideno-Dmanitol $(30,0 \mathrm{~g}, 112,7 \mathrm{mmol})$ em $300 \mathrm{~mL}$ de solução de bicarbonato de sódio $5 \%(\mathrm{~m} / \mathrm{v})$, sob agitação constante a $0{ }^{\circ} \mathrm{C}$, foram adicionados $90 \mathrm{~mL}$ de solução saturada de periodato de sódio, gota a gota. A reação foi mantida sob agitação constante, à temperatura ambiente, por $1 \mathrm{~h}$, sendo em seguida adicionados $100 \mathrm{~mL}$ de etanol. $\mathrm{O}$ extrato etanólico foi filtrado, fornecendo 3 , que foi utilizado sem purificação prévia na reação seguinte.

O filtrado, contendo 2,3-O-isopropilideno-D-gliceraldeído (3), foi resfriado a $0{ }^{\circ} \mathrm{C}$, tratado com $\mathrm{NaBH}_{4}(8,5 \mathrm{~g}, 225,2 \mathrm{mmol})$ e mantido sob agitação por $2 \mathrm{~h}$. A mistura reacional foi filtrada e em seguida adicionaram-se $200 \mathrm{~mL}$ de clorofórmio e ácido acético, a $0{ }^{\circ} \mathrm{C}$, sob agitação, até $\mathrm{pH}$ 8. Após $10 \mathrm{~min}$, a mistura foi extraída com 6 x $200 \mathrm{~mL}$ de clorofórmio. Os extratos reunidos foram tratados com sulfato de sódio, o solvente foi evaporado à pressão reduzida e o produto bruto foi destilado em aparelhagem Kugelrhor, fornecendo o produto 4 , um óleo amarelo claro, com $85 \%(25,5 \mathrm{~g})$ de rendimento, p.e.: $105^{\circ} \mathrm{C}(71 \mathrm{mmHg})$, lit.: $82^{\circ} \mathrm{C}$ $(13 \mathrm{mmHg}) ;{ }^{20}[\alpha]_{\mathrm{D}}^{20}:+14,7$ (puro), lit.: $+14,5$ (puro) $;{ }^{20} \mathrm{IV} \mathrm{v}^{\mathrm{NaCl}}$ : $3450,2990,2940,1382,1372,1215$ e $1155 \mathrm{~cm}^{-1}$; RMN de ${ }^{1} \mathrm{H}(300$ $\left.\mathrm{MHz}, \mathrm{CDCl}_{3}\right) \delta: 4,40-3,55(\mathrm{~m}, 5 \mathrm{H}), 2,80\left(\mathrm{sl}, 1 \mathrm{H}\right.$, troca com $\mathrm{D}_{2} \mathrm{O}$, $\mathrm{OH}), 1,45$ e $1,39\left(2 \mathrm{~s}, 6 \mathrm{H}, 2 \mathrm{CH}_{3}\right.$ gem $)$ ppm; RMN de ${ }^{13} \mathrm{C}(75,5$ $\mathrm{MHz}, \mathrm{CDCl}_{3}$ ) $\delta:$ 108,9 (C-quaternário), 76,7 (C-2), 66,8 (C-1),
63,1 (C-3), 27,3 e 26,9 (2 $\mathrm{CH}_{3}$ gem) ppm; EM m/z: [M - H] $]^{+}: 131$ $(-1,1 \%),\left[\mathrm{M}^{+}-\mathrm{CH}_{3}\right]: 117(53 \%), 101(45 \%), 61(32 \%), 59(38 \%)$, $57(53 \%), 43(100 \%)$.

\section{(S)-2,2-dimetil-4-tosiloximetil-1,3-dioxolano $(5)^{30}$}

A uma solução do cetal cíclico 4 (14,0 g, $106 \mathrm{mmol})$ em 8,57 $\mathrm{mL}$ de piridina a $0{ }^{\circ} \mathrm{C}$, foi adicionado cloreto de $p$-toluenossulfonila (20,2 g, $106 \mathrm{mmol})$, sob agitação constante. A reação foi mantida a 0 ${ }^{\circ} \mathrm{C}$ por $30 \mathrm{~min}$, e à temperatura ambiente, por $12 \mathrm{~h}$, sendo em seguida adicionados $16 \mathrm{~g}$ de gelo. A fase aquosa foi extraída com 3 × $30 \mathrm{~mL}$ de éter etílico e o extrato etéreo foi lavado com solução de sulfato de cobre $10 \%$, seco com sulfato de sódio e o solvente evaporado sob pressão reduzida. O produto bruto foi purificado por cromatografia acelerada radialmente (chromatotron), utilizando como eluente éter de petróleo/éter etílico 1:1, fornecendo 94\% (13,2 g) de rendimento do produto monotosilado 5. [ $\alpha]_{\mathrm{D}}^{20}:-6,71$ (puro); IV $v^{\mathrm{NaCl}}$ : 2990, 2980, 1600, 1380, 1250, 1190, 1180, $900 \mathrm{~cm}^{-1}$; RMN de ${ }^{1} \mathrm{H}(300 \mathrm{MHz}$, $\left.\mathrm{CCl}_{4}+\mathrm{CDCl}_{3}\right) \delta: 7,80(\mathrm{~d}, 2 \mathrm{H}, J=8,2 \mathrm{~Hz}), 7,36(\mathrm{~d}, 2 \mathrm{H}, J=8,2 \mathrm{~Hz})$, 4,20-3,80 (m, 5H), 2,45 (s, 3H), 1,35 (s, 3H), 1,30 (s, 3H) ppm; RMN de ${ }^{13} \mathrm{C}\left(75,5 \mathrm{MHz}, \mathrm{CCl}_{4}+\mathrm{CDCl}_{3}\right) \delta: 145,3(\mathrm{C}-4), 132,4(\mathrm{C}-1), 130,0$ (C-2, C-6), 128,2 (C-3, C-5), 110,0 (C-quaternário), 75,0 (C-2`), 68,4 (C-1'), 63,5 (C-3'), 26,9 e 26,7 (2 $\mathrm{CH}_{3}$ gem), 21,7 ( $\mathrm{CH}_{3}$-arila) ppm; EM m/z: [M+ $\left.-\mathrm{CH}_{3}\right]: 271$ (44\%), 155 (37\%), 101 (87\%), 91 (69\%), $43(100 \%)$.

\section{(S)-4-pentil-2,2-dimetil-1,3-dioxolano $(6)^{21}$}

A uma suspensão de iodeto cuproso $(7,9 \mathrm{mg}, 41,6 \mu \mathrm{mol})$ em éter etílico $(50 \mathrm{~mL})$ a $-40{ }^{\circ} \mathrm{C}$, sob atmosfera de argônio e agitação constante, foi adicionado, gota a gota, n-butil lítio em hexano $(52 \mathrm{~mL}, 83$ mmol). A agitação permaneceu por $30 \mathrm{~min}$, em seguida, adicionou-se a solução do tosilato 5 (8,32 g, 29,1 mmol) em éter etílico $(50 \mathrm{~mL})$ gota a gota a $-78{ }^{\circ} \mathrm{C}$. A agitação permaneceu por $45 \mathrm{~min}$, a mistura reacional foi diluída com $50 \mathrm{~mL}$ de solução aquosa de cloreto de amônio $10 \%$ e extraída com éter etílico. O extrato etéreo foi lavado com solução saturada de $\mathrm{NaCl}$, tratado com sulfato de sódio e concentrado a vácuo. Após cromatografia acelerada radialmente (chromatotron), utilizando-se um gradiente de eluição da mistura éter de petróleo/éter etílico, obteve-se $95 \%$ (7,90 g) de rendimento de 6 um óleo viscoso.

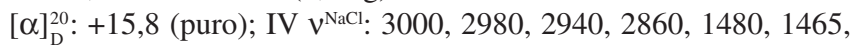
1390, 1380, 1260, 1065, 980, 865, $830 \mathrm{~cm}^{-1}$; RMN de ${ }^{1} \mathrm{H}(300 \mathrm{MHz}$, $\left.\mathrm{CCl}_{4}+\mathrm{CDCl}_{3}\right) \delta: 4,20-3,20(\mathrm{~m}, 3 \mathrm{H}), 1,80-1,10(\mathrm{~m}, 14 \mathrm{H}), 1,28(\mathrm{~s}$, $3 \mathrm{H}), 1,24$ (s, 3H), 0,90 (m, 3H) ppm; RMN de ${ }^{13} \mathrm{C}\left(75,5 \mathrm{MHz}, \mathrm{CCl}_{4}\right.$ + $\mathrm{CDCl}_{3}$ ) $\delta:$ 108,6 (C-quartenário), 76,2 (C-2), 69,5 (C-1), 33,4, (C3), 27,9 (C-4), 26,8 e 27,0 (2 CH gem), 25,7 (C-5), 22,7 (C-6), 14,3 (C-7) ppm; EM m/z: [M+ - $\left.\mathrm{CH}_{3}\right]: 157$ (42\%), 101 (87\%), 61 (22\%), $57(69 \%), 43(100 \%)$

\section{(S)-(-)-1,2-heptanodiol (7) ${ }^{7}$}

A uma solução do acetonídeo alquilado 6 (1,72 g, 0,1 mol) em metanol $(10 \mathrm{~mL})$ adicionou-se ácido clorídrico $(15 \mathrm{~mL}, 1 \mathrm{~mol} \mathrm{~L}-1)$, mantendo-se a mistura reacional sob refluxo, por $4 \mathrm{~h}$. O metanol foi removido sob pressão reduzida e a fase aquosa foi saturada com cloreto de sódio e extraída com 6 x $10 \mathrm{~mL}$ de éter etílico. Os extratos reunidos foram tratados com sulfato de sódio, o solvente foi evaporado à pressão reduzida e o produto bruto foi purificado por cromatografia em coluna de gel de sílica, eluída com um gradiente éter de petróleo/ éter etílico, fornecendo o diol $7 \mathrm{com} 95 \%(1,63 \mathrm{~g})$ de rendimento. $[\alpha]_{\mathrm{D}}^{20}$ : $-15,4$ (c = 2,0, EtOH), lit.: -15,2 (c = 1,67, EtOH) $;^{24} \mathrm{IV} v^{\mathrm{NaCl}}: 3362$, 2956, 2860, 1459, 1072, $1027 \mathrm{~cm}^{-1} ; \mathrm{RMN}$ de ${ }^{1} \mathrm{H}\left(300 \mathrm{MHz}, \mathrm{CDCl}_{3}\right)$ $\delta: 3,80\left(\mathrm{sl}, 2 \mathrm{H}\right.$, troca com $\left.\mathrm{D}_{2} \mathrm{O}, 2 \times \mathrm{OH}\right), 3,67(\mathrm{~m}, 1 \mathrm{H},-\mathrm{CH}(\mathrm{OH})-)$, $3,60\left(\mathrm{dd}, 1 \mathrm{H},-\mathrm{CH}_{2}-\mathrm{OH}\right), 3,40\left(\mathrm{dd}, 1 \mathrm{H}, \mathrm{J}_{\mathrm{gem}}=11,2 \mathrm{~Hz}\right.$ e $\mathrm{J}_{\text {vic }}=7,8 \mathrm{~Hz}$, $\left.-\underline{\mathrm{C}}_{2} \mathrm{OH}\right), 1,40$ (m, 2H, $\left.-\underline{\mathrm{C}}_{2}-\mathrm{CHOH}\right), 1,38\left(\mathrm{~m}, 6 \mathrm{H}, 3 \times \mathrm{CH}_{2}\right), 0,90$ $\left(\mathrm{t}, 3 \mathrm{H}, \mathrm{J}=6,6 \mathrm{~Hz}, \mathrm{CH}_{3}\right) \mathrm{ppm}$; $\mathrm{RMN} \mathrm{de}{ }^{13} \mathrm{C}\left(75,5 \mathrm{MHz}, \mathrm{CDCl}_{3}\right) \delta$ : 
72,3 (C-2), 66,6 (C-1), 33,0 (C-3), 31,8 (C-4), 25,2 (C-5), 22,5 (C-

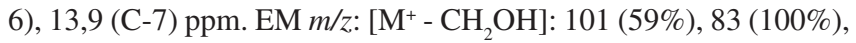
$\left[\mathrm{M}^{+}-\left(\mathrm{CH}_{2}\right)_{4} \mathrm{CH}_{3}\right]: 61(37 \%), 55(23 \%)$.

\section{(S)-2-acetoxi -1-bromo-heptano (8) e (R) -1-acetoxi -2-bromo-} heptano $(\mathbf{9})^{22-24}$

Uma solução de ácido bromídrico em ácido acético (8,1 g, 34,2 mmol) foi adicionada ao diol (7) (1,5 g, 11,4 mmol), sob agitação constante, em banho de gelo. Após 5 min, o banho de gelo foi removido e a mistura permaneceu sob agitação por $30 \mathrm{~min}$. Adicionou-se $25 \mathrm{~mL}$ de água, em seguida a solução foi neutralizada com carbonato de sódio e extraída com éter etílico ( 3 x 20 mL). Os extratos combinados foram tratados com sulfato de sódio. O solvente foi evaporado à pressão reduzida, obteve-se o produto bruto, o qual, por purificação em coluna cromatográfica de gel de sílica, eluída com diclorometano, forneceu a mistura de $\mathbf{8}$ e $\mathbf{9}$, com $85 \%(7,0 \mathrm{~g})$ de rendimento, respectivamente, na proporção de (94:6). IV $\mathrm{v}^{\mathrm{NaCl}}$ : 2956, 2931, 2860, 1743 , $1372,1235,1025,604 \mathrm{~cm}^{-1}$; RMN de ${ }^{1} \mathrm{H}\left(300 \mathrm{MHz}, \mathrm{CDCl}_{3}\right) \delta: 5,00$ (quint., $1 \mathrm{H}, \mathrm{J}=5,2 \mathrm{~Hz}), 3,54-3,48\left(\mathrm{dd}, 1 \mathrm{H}, \mathrm{J}_{\text {gem }}=10,8 \mathrm{~Hz}\right.$ e $\mathrm{J}_{\text {vic }}=$ $4,5 \mathrm{~Hz}), 3,45-3,40\left(\mathrm{dd}, 1 \mathrm{H}, \mathrm{J}_{\mathrm{gem}}=10,8 \mathrm{~Hz}\right.$ e J vic $\left.=5,4 \mathrm{~Hz}\right), 2,09(\mathrm{~s}$, $3 \mathrm{H}), 1,68(\mathrm{~m}, 2 \mathrm{H}), 1,30(\mathrm{~m}, 6 \mathrm{H}), 0,89(\mathrm{t}, 3 \mathrm{H}, J=6,6 \mathrm{~Hz}) \mathrm{ppm}$; RMN de ${ }^{13} \mathrm{C}\left(75,5 \mathrm{MHz}, \mathrm{CDCl}_{3}\right) \delta: 170,7(\mathrm{C}-1), 72,6(\mathrm{C}-2), 34,3(\mathrm{C}-3)$, 32,5 (C-4), 31,5 (C-5), 24,8 (C-6), 22,5 e 21,0 (C-grupo acetila), 14,0 (C-7) ppm; EM m/z: [M+ - $\left.\mathrm{CH}_{3} \mathrm{COOH}\right]: 176(2 \%),\left[\mathrm{M}^{+}-\mathrm{Br}\right]: 157$ (2\%), 97 (33\%), 55 (55\%), 43 (100\%).

\section{(S)-(-)-1,2-epoxi-heptano $(10)^{24}$}

Uma solução de hidróxido de potássio (120 mg, 2,2 mmol) em metanol $(1 \mathrm{~mL})$ foi adicionada à mistura de regioisômeros 8 e 9 (536,4 mg, 2,2 mmol). Após $20 \mathrm{~min}$, adicionou-se água para dissolver o brometo de potássio e a solução foi extraída com pentano $(5 \times 10$ $\mathrm{mL}$ ). Os extratos combinados foram lavados com solução saturada de cloreto de sódio e tratados com sulfato de sódio. O solvente foi eliminado por destilação fracionada utilizando-se uma coluna de Vigreux. $\mathrm{O}$ resíduo oleoso $\mathbf{1 0}$ incolor foi obtido com rendimento quantitativo. $[\alpha]_{\mathrm{D}}^{20}:-15,1(\mathrm{c}=2,0, \mathrm{EtOH})$, lit.: $-15,6(\mathrm{c}=1,8, \mathrm{EtOH}),{ }^{21}-14,0(\mathrm{c}=$ $2,3, \mathrm{EtOH}) ;{ }^{24} \mathrm{IV} \mathrm{v}{ }^{\mathrm{NaCl}}: 2960,1461,1251,905,830 \mathrm{~cm}^{-1} ; \mathrm{RMN}$ de ${ }^{1} \mathrm{H}$ (300 MHz, $\left.\mathrm{CDCl}_{3}\right) \delta: 2,93$ - 2,88 (m, 1H, -CH, C-2), 2,76 - 2,73 (dd, $1 \mathrm{H},-\mathrm{CH}_{2}, \mathrm{C}-1, \mathrm{~J}_{\text {gem }}=5,5 \mathrm{~Hz}$ e J $\left.{ }_{\text {vic }}=4,0 \mathrm{~Hz}\right), 2,48-2,45\left(\mathrm{dd}, 1 \mathrm{H},-\mathrm{C}_{2}\right.$, $\mathrm{C}-1, \mathrm{~J}_{\mathrm{gem}}=5,5 \mathrm{~Hz}$ e $\left.\mathrm{J}_{\text {vic }}=2,8 \mathrm{~Hz}\right), 1,56-1,41\left(\mathrm{~m}, 2 \mathrm{H},-\mathrm{CH}_{2}, \mathrm{C}-3\right)$, 1,37 - 1,24 (m, 6H, - $\underline{\mathrm{H}}_{2}, \mathrm{C}-4, \mathrm{C}-5$ e C-6), $0,92-0,84$ (t, 3H, $\left.\underline{\mathrm{H}}_{3}\right)$ ppm. RMN de ${ }^{13} \mathrm{C}\left(75,5 \mathrm{MHz}, \mathrm{CDCl}_{3}\right) \delta: 52,4(\mathrm{C}-2), 47,1$ (C-1), 32,4 (C-3), 31,6 (C-5), 25,6 (C-4), 22,5 (C-6), 13,9 (C-7) ppm. EM m/z: $\left[\mathrm{M}^{+}-\mathrm{CH}_{3}\right]: 99(2 \%),\left[\mathrm{M}^{+}-\mathrm{COCH}_{3}\right]: 71(100 \%), 67,56(46 \%), 41$.

\section{(S)-1-fenil-1-nonin-4-ol (11 ${ }^{26}$}

Uma solução de n-butil lítio em hexano $(0,8 \mathrm{~mL}, 1,5 \mathrm{mmol})$ foi adicionada a uma solução de fenilacetileno destilado $(153 \mathrm{mg}, 1,5$ mmol) em tetraidrofurano $(2 \mathrm{~mL})$ a $-78^{\circ} \mathrm{C}$ sob agitação constante e atmosfera de argônio. A mistura permaneceu sob agitação por $10 \mathrm{~min}$. Em seguida, trifluoreto de boro eterato $(0,2 \mathrm{~mL})$ foi adicionado e a agitação permaneceu por $10 \mathrm{~min}$ a $-78^{\circ} \mathrm{C}$. Adicionou-se uma solução de 1,2-epoxi-heptano (10) (114 mg, $1 \mathrm{mmol}$ ) em tetraidrofurano ( $1 \mathrm{~mL})$, após agitação durante $30 \mathrm{~min}$ a $-78^{\circ} \mathrm{C}$, a reação foi interrompida pela adição de solução saturada de cloreto de amônio. A fase orgânica foi extraída com acetato de etila e tratada com sulfato de sódio. O solvente foi eliminado por evaporação à pressão reduzida e a purificação do produto bruto foi realizada em coluna cromatográfica de gel de sílica, eluída com $15 \%$ de acetato de etila em éter de petróleo obtendo-se (80 mg) 70\% de rendimento da mistura de regioisômeros $\mathbf{1 1}$ e 12, na proporção de (91:9), conforme determinado pela integração dos sinais no espectro de RMN de ${ }^{1} \mathrm{H}$. IV $v^{\mathrm{NaCl}}$ : 3374; 3056; 2930; 2858; 2247 ; 1598; 1490; 1466; 1442; 1378; 1124; 1070; 1028; 691; 526;
$500 \mathrm{~cm}^{-1} ; \mathrm{RMN}^{\mathrm{de}}{ }^{1} \mathrm{H}\left(300 \mathrm{MHz}, \mathrm{CDCl}_{3}\right) \delta: 7,34$ (m, 2H, H-2', H-6'), 7,25 (m, 3H, H-3', H-4', H-5), 3,82 (quint, 1H, J = 6,0 Hz, H-4), $2,68\left(\mathrm{dd}, 1 \mathrm{H}, J=16,7 \mathrm{~Hz}, \mathrm{~J}_{\text {vic }}=4,8 \mathrm{~Hz}, \mathrm{H}-3\right), 2,50\left(\mathrm{dd}, 1 \mathrm{H}, \mathrm{J}_{\text {gem }}=\right.$ $16,7, \mathrm{~J}_{\text {vic }}=6,6 \mathrm{~Hz}, \mathrm{H}-3$ '), 2,07 (sl, 1H, OH), 1,58 (m, 2H, H-5), 1,34 (m, 6H, H-6, H-7, H-9), 0,92 (t, 3H, 6,7 Hz, H-9) ppm; RMN de ${ }^{13} \mathrm{C}$ (75,5 MHz, $\mathrm{CDCl}_{3}$ ) $\delta: 131,7$ (C-2', C-6'), 128,3 (C-3', C-5'), 127,9 (C-4'), 123,4 (C-1'), 86,2 (C-1), 83,0 (C-2), 70,2 (C-4), 36,2 (C-5), 31,6 (C-7), 28,3 (C-3), 25,2 (C-6), 22,5 (C-8), 13,9 (C-9) ppm; EM $m / z:\left[\mathrm{M}^{+}\right]: 216(2 \%), 116(100 \%), 115(46 \%), 83(9 \%), 55(27 \%)$.

\section{CONCLUSÃO}

A partir de D-manitol, foram obtidas 9 substâncias, cujas estruturas foram confirmadas através das análises dos respectivos valores de $\alpha_{D}$ e dados espectrais. As substâncias foram preparadas com bons rendimentos a partir do cetal cíclico, isopropilideno glicerol (4). O estudo preliminar da atividade antibacteriana dos regioisômeros quirais mostrou tratar-se de uma mistura ativa contra E. coli, indicando que a presença do grupo fenila ligado ao carbono acetilênico, além de uma cadeia hidrofóbica e a quiralidade são fatores estruturais importante para a atividade antibacteriana desta classe de compostos.

\section{AGRADECIMENTOS}

Ao CNPq e à CAPES pelas bolsas concedidas. À Prof. Dra. S. M. N. Gimenez pelas análises de atividade antibacteriana.

\section{REFERÊNCIAS}

1. Oliveira, P. S. M.; Ferreira, V. F.; Souza, M. V. N.; Carvalho, E. M.; Quim. Nova 2008, 31, 776.

2. Ringenbach, F.; Touzan, P.; Rude, M. F.; Laugier, J. P.; FRA PI 9.200.786-4, 1992.

3. Dueholm, K. L.; Pedersen, E. B.; Synthesis 1992, 1.

4. Ghosh, A. K.; McKee, S. P.; Thompson, W. J.; Tetrahedron Lett. 1991, 32,5729 .

5. Avignon-Tropis, M.; Berjeaud, J. M.; Pougny, J. R.; Frechard-Orturno, I.; Guillerm, D.; Linstrumelle, G.; J. Org. Chem. 1992, 57, 651.

6. Merrer, Y. L.; Pelletier, C. G.; Languin, D. M.; Mestre, F.; Dureault, A.; Depezay, J. C.; J. Org. Chem. 1989, 54, 2409.

7. Jhonson, F.; Paul, K. G.; Favara, D.; Ciabatti, R.; Guzzi, U.; J. Am. Chem. Soc. 1982, 104, 2190.

8. Molinari, F.; Gandolfi, R.; EP1413627, 2004.

9. Nataro, J. P.; Kaper, J. B.; Clin. Microbiol. Rev. 1998, 11, 142.

10. Menezes, C. A.; Gonçalves, D. S.; Amianti, J.; Fernandes, I.; Taddei, C. R.; Koga, P. C. M.; Trabulsi, L. R.; Martinez, M. B.; Piazza, R. M. F.; Braz. J. Microbiol. 2003, 34, 11.

11. Swaminathan, B.; Barrett, T. J.; Hunter, S. B.; Tauxe, R. V.; Emerging Infectious Diseases 2001, 7, 382.

12. Taha, A. A.; Phytochemistry 2000, 55, 921; Magalhães, A. F.; Vieira, D. M.; Magalhães, E. G.; Quim. Nova 1990, 13, 65; Dabrowski, Z.; Wrobel, J. T.; Wojtasiewicz, K.; Phytochemistry 1980, 19, 2464.

13. Watanabe, K.; Tsuda, Y.; Hamada, M.; Omori, M.; Mori, G.; Iguchi, K.; Naoki, H.; Fujita, T.; Soest, R. W. M. V.; J. Nat. Prod. 2005, 68, 1001; Youssef, D. T. A.; Soest, R. W. M. V.; Fusetani, N.; J. Nat. Prod. 2003, 66, 861; Lim, Y. J.; Lee, C.; Hong, J.; Kim, D.; Im, K. S.; Jung, J. H.; J. Nat. Prod. 2001, 64, 1565.

14. Yadav, J. S.; Maiti, A.; Tetrahedron Lett. 2001, 42, 3909; Harkat, H.; Weibel, J.; Pale, P.; Tetrahedron Lett. 2007, 48, 1439; Vizer, S. A.; Yerzhanov, K. B.; Quntar, A. A. A. A.; Dembitsky, V. M.; Tetrahedron 2004, 60, 5499.

15. Hallock, Y. F.; Cardellina II, J. H.; Balaschak, M. S.; Alexander, M. R.; Prather, T. R.; Shoemaker, R. H.; Boyd, M. R.; J. Nat. Prod. 1995, 58, 1801. 
16. Yamazaki, M.; Hirakura, K.; Miyaichi, Y.; Imakura, K.; Kita, M.; Chiba K.; Mohri, T.; Biol. Pharm. Bull. 2001, 24, 1434.

17. López, S.; Fernández-Trillo, F.; Castedo, L.; Saá, C.; Org. Lett. 2003, 5, 3725; Dembitsky, V. M.; Levitsky, D. O.; Gloriozova, T. A.; Poroikov, V. V.; Nat. Prod. Commun. 2006, 1, 773.

18. Baer, E.; Biochem. Prepn. 1952, 2, 31; Baer, E.; Fischer, H. O. L.; J. Biol. Chem. 1939, 128, 463.

19. Takano, S.; Kurotaki, A.; Takahashi, M.; Ogasawara, K.; Synthesis 1986, $5,403$.

20. Lecocq, J.; Ballou, C. E.; Biochemistry 1964, 3, 976; Alvarenga, E. S.; Carneiro, V. M. T.; Silvério, F. O.; Saliba, W. A.; J. Chil. Chem. Soc. 2006, 51, 986.

21. Schmidt, U.; Talbiersky, J.; Bartkowiak, F.; Wild, J.; Angew. Chem., Int. Ed. 1980, 19, 198.

22. Hoyer, T.; Kjae, A.; Lykkesfeldt, J.; Collect. Czech. Chem. Commun. 1991, 56, 1042.
23. Golding, B. T.; Hall, D. R.; Sakrikar, S.; J. Chem. Soc. Perkin I 1973, 1214.

24. Mori, K.; Agric. Biol. Chem. 1976, 40, 1617.

25. Brandsma, L.; Preparative Acetylenic Chemistry, $2^{\text {nd }}$ ed., Elsevier: Oxford, 1988.

26. Yamaguchi, M.; Hirao, I.; Tetrahedron Lett. 1983, 24, 391.

27. Andricopulo, A. D.; Yunes, R. A.; Nunes, R. J.; Savi, A. O. S.; Corrêa, R.; Cruz, A. B.; Cechinel Filho, V.; Quim. Nova 1998, 21, 573.

28. Lima, V. L. E.; Quim. Nova 1997, 20, 657.

29. Gimenez, S. M. N.; Tese de Doutorado, Universidade Estadual de Campinas, Brasil, 1994.

30. Holy, A.; Collect. Czech. Chem. Commun. 1982, 47, 173; Valverde, S.; Herradon, B.; Rosenal, R. M.; Lomas, M. M.; Can. J. Chem. 1987, 65, 332 